\title{
Three sequential outbreaks of Group A Streptococcus over a two-year period at the Canadian Forces Leadership and Recruit School, St. Jean Garrison, Québec
}

\author{
Barbara Strauss ${ }^{1 \star}$, Martin Tepper ${ }^{1}$, Diane Luํ․ François Gagnon², Eric Girard², Walter Demczuk ${ }^{3}$, \\ Irene Martin ${ }^{3}$, Martine Massé ${ }^{2}$, Kirsten Barnes ${ }^{1}$
}

\section{Abstract}

Background: Since December 2016, the basic military training (BMT) facility for the Canadian Armed Forces (CAF) has experienced repeated outbreaks of Group A Streptococcus (GAS). In 2018, a voluntary mass antibiotic prophylaxis (MAP) program was implemented to interrupt GAS transmission among recruits. The objective of this study was to describe the epidemiology of three GAS outbreaks and a period of increased pharyngitis infections at the CAF BMT facility in Québec over a two-year span, and to detail the prevention and control measures implemented to mitigate the risk to recruit health.

Methods: Descriptive data were collected on invasive and severe GAS cases along with laboratory data including genotyping of throat swabs from recruits presenting with pharyngitis. A laboratory-based acute respiratory infection surveillance system was used to aid in monitoring and decision-making. Close contacts of recruits were assessed for asymptomatic GAS carriage and MAP adverse events surveillance was conducted.

Results: Three distinct GAS outbreaks occurred at the Canadian Forces Leadership and Recruit School totaling eight invasive (iGAS) and 13 severe (sGAS) cases over two years. All iGAS/sGAS cases, apart from one instructor, were among recruits. The predominant strain in all three outbreaks was type emm6.4. A total of 11,293 recruits received MAP (penicillin G benzathine or azithromycin) between March 7, 2018 and November 18, 2019. There were eight reported serious adverse events related to penicillin administration.

Conclusion: The CAF BMT facility experienced three GAS outbreaks over the course of two years, and despite the use of enhanced hygiene measures, only MAP has been effective in quelling these outbreaks.
This work is licensed under a Creative Commons Attribution 4.0 International License.
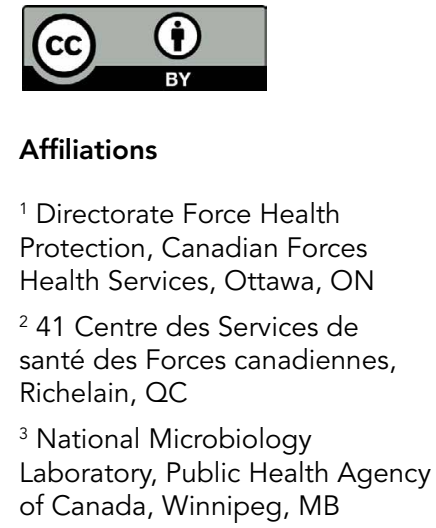

${ }^{3}$ National Microbiology Laboratory, Public Health Agency of Canada, Winnipeg, MB

${ }^{\star}$ Correspondence: barbara.strauss@forces.gc.ca

Suggested citation: Strauss B, Tepper M, Lu D, Gagnon F, Girard E, Demczuk W, Martin I, Massé M, Barnes K. Three sequential outbreaks of Group A Streptococcus over a two-year period at the Canadian Forces Leadership and Recruit School, St. Jean Garrison, Québec. Can Commun Dis Rep 2020;46(9):256-63.

https://doi.org/10.14745/ccdr.v46i09a02

Keywords: infectious disease outbreaks, military recruits, Canada, Streptococcus pyogenes, mass antibiotic prophylaxis

\section{Background}

Streptococcus pyogenes (S. pyogenes) or Group A

Streptococcus (GAS) is a Gram-positive bacterium that manifests in various illnesses ranging from mild non-invasive diseases, such as acute pharyngitis, tonsillitis and impetigo, to severe invasive diseases, such as bacteremia, pneumonia, necrotizing fasciitis and streptococcal toxic shock syndrome. Although mild pharyngeal infections are readily treatable with appropriate antibiotics, invasive disease is associated with substantial morbidity and mortality. Characterization of GAS strains is done through molecular sequencing of the emm gene encoding the 
M protein; a predominant virulence surface protein. Although there are currently over $240 \mathrm{emm}$ types, a relatively small number of types cause the majority of disease (1).

The incidence of invasive Group A Streptococcus (iGAS) has been increasing in Canada over the past decade (2) and a number of provinces, including Québec and Ontario, have experienced multiple GAS outbreaks since 2016 (3-5). Long term care facilities, homeless shelters and marginalized persons, such as those who use drugs, have been particularly affected (emm types 118, 81, 74 and 9) (3-5).

The United States (US) military experienced recurrent outbreaks of iGAS dating back to the 1940s in their recruit population (6). Despite efforts by the US military to prevent GAS transmission, through hand hygiene, cough etiquette, head-to-toe sleeping arrangements and reduction of crowding when possible, outbreaks continued among recruits (7). It was only through the administration of prophylactic antibiotics first initiated during the mid-1950s that infections and related sequelae were reduced (7). These early studies also found that administration of 1.2 million units of intramuscular penicillin $G$ benzathine (PGB) was more effective than oral penicillin and compliance was considerably higher (8). As well, when mass prophylaxis was discontinued, GAS-related outbreaks recurred among many recruit installations, underscoring the effectiveness of PGB and azithromycin in preventing GAS-related outbreaks in this population $(9,10)$. The Canadian Armed Forces (CAF) experienced their first iGAS outbreak among their recruit population in December 2016. In this article, we describe three successive GAS outbreaks and one notable increase in non-invasive GAS infections at the Canadian Forces Leadership and Recruit School (CFLRS), the basic military training (BMT) facility for the CAF at St. Jean Garrison, Québec (Appendix A) and assess the impact of mass antibiotic prophylaxis (MAP).

\section{Methods}

All investigations of GAS infections at CFLRS were approved under the authority of the CAF Surgeon General. Descriptive statistics were used to characterize the outbreaks and national case definitions were used to define confirmed and probable iGAS cases (11). Case definitions for confirmed and probable severe non-invasive GAS cases were also developed (Appendix B).

\section{Laboratory data}

Throat swabs were taken from symptomatic recruits based on a Mclsaac score (12) of at least two, and a subset of positive throat swabs from each outbreak were sent for molecular typing and genomic sequencing. Emm typing was performed by polymerase chain reaction and deoxyribonucleic acid sequencing using the Centre for Disease Control emm database (13).
Genomic analyses were performed as previously described (14). A laboratory-based acute respiratory infection surveillance program, based on a US military surveillance system (15), was implemented using throat swab results to monitor acute respiratory disease (ARD) trends. The threshold level for action consisted of two metrics: 1) the ARD rate, defined as the weekly number of GAS throat swabs collected divided by the weekly recruit population; and 2) the acute streptococcal disease (ASD) rate, defined as the weekly number of positive GAS throat swabs divided by the weekly recruit population. Thresholds to flag evolving outbreaks were set at an ARD rate of at least 1.5 per 100 recruits or an ASD rate of at least 0.25 per 100 recruits for two consecutive weeks (Figure 1) (15).

Figure 1: Weekly acute respiratory disease rate and acute streptococcal disease rate, Canadian Forces Leadership and Recruit School, 2017-2019

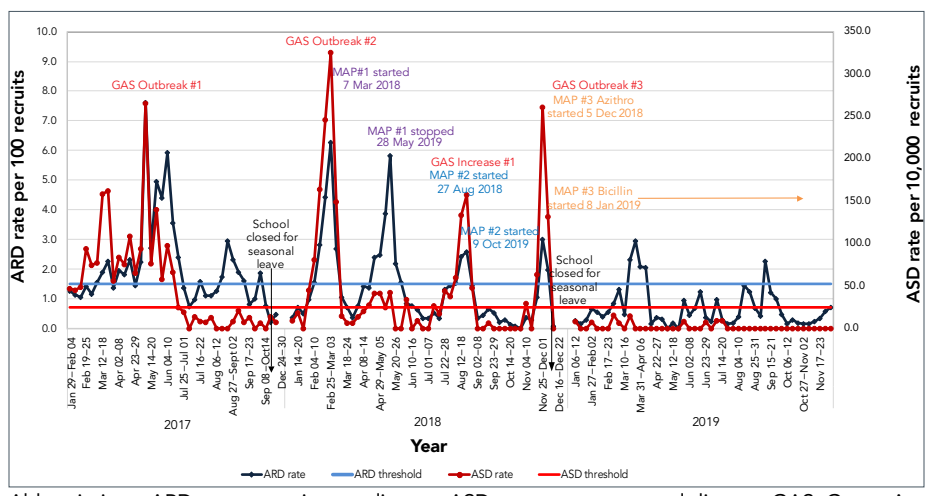

Abbreviations: ARD, acute respiratory disease; ASD, acute streptococcal disease; GAS, Group A Streptococcus; MAP, mass antibiotic prophylaxis

\section{Mass antibiotic prophylaxis (penicillin G benzathine and azithromycin)}

Numbers and percentages were used to monitor coverage and refusal rates of MAP among recruits and instructors, and any associated adverse events.

\section{Group A Streptococcus pharyngeal carriage study}

To look for asymptomatic GAS pharyngeal carriers (emm6.4), a GAS carriage study among instructors in close contact with recruits was conducted during the first outbreak and in October of 2018 following the second outbreak. For the latter, instructors who had close contact with recruits and were present during both the 2017 and 2018 GAS outbreaks were included. Instructors provided informed consent to a throat swab on a voluntary basis. Close contact was defined according to the iGAS household contact criteria of either spending at least four hours per day on average in a week, or a total of 20 hours per week with recruits. 


\section{Results}

\section{Outbreak 1}

The details of the first GAS outbreak at CFLRS have been previously described (14). Between December 2016 and April 2017, four iGAS cases (three cases [two confirmed and one probable] of pneumonia with empyema and one confirmed case of necrotizing fasciitis) and six non-invasive severe GAS cases (four severe pharyngitis and/or sinusitis and two pneumonias) occurred among recruits and one instructor. Positive GAS throat cultures among recruits had increased substantially beginning in November of 2016 . Of the 120 cultures sequenced, $80 \%$ were emm6.4, which were highly related as per phylogenetic cluster analysis. The majority of GAS-positive cultures were from young (mean age 24 years) male $(69.4 \%)$ recruits $(89.5 \%)$, reflecting the population demographics of CFLRS. All 31 instructors $(40 \%$ of instructors who had contact with a confirmed or probable case) who presented for screening had a negative GAS culture. Standard control measures were implemented during this outbreak and some are still in place (Table 1).

\section{Outbreak 2}

The second GAS outbreak at CFLRS occurred February 11 to March 11, 2018 with two iGAS cases (one confirmed necrotizing fasciitis, one probable meningitis) and four severe non-invasive cases (one cellulitis, three pneumonias) among recruits. Of the six invasive and severe GAS cases, four were male and two were female (age range 18-45 years). The average number of days from arrival to symptom onset was 38 days (range 14-58 days). During the one month period, 84 (69\%) of 122 positive GAS throat swabs were emm6.4. The average age of recruits with a positive GAS swab was 24 years (range 18-49 years). Close contacts (all recruits within a platoon) of invasive and severe cases received postexposure prophylaxis according to the Public Health Agency of Canada Guidelines (6).

Given type emm6.4 persisted, close contacts (mainly instructors) of recruits were asked to undergo voluntary screening by the Base Surgeon (the physician responsible for health care for the St. Jean Garrison) without any reprisal for asymptomatic GAS carriage for the second time. A total of 207 instructors were eligible for screening. At the time of screening, one instructor was symptomatic and 39 others were posted off base, leaving 167 instructors. After seven days of collection, 115 (69\%) of 167 throat swabs from instructors were submitted for culture. Seven (6\%) of 115 swabs were GAS positive; three of these were type emm6.4. Of the three positive emm6.4 cultures, one instructor refused eradication treatment, another instructor received eradication treatment but had no post-treatment swab to assess carriage status and one instructor was successfully treated as evidenced by a negative GAS throat swab post treatment.
Table 1: Infection control measures implemented during each outbreak at the Canadian Forces Leadership and Recruit School, 2017-2019

\begin{tabular}{|c|c|c|c|}
\hline Measures implemented & $\begin{array}{c}\text { Outbreak } \\
1\end{array}$ & $\begin{array}{c}\text { Outbreak } \\
2\end{array}$ & $\begin{array}{c}\text { Outbreak } \\
3\end{array}$ \\
\hline $\begin{array}{l}\text { Enhanced hand hygiene } \\
\text { and cough etiquette and } \\
\text { symptom recognition with } \\
\text { augmented prevention } \\
\text { signage. Briefing of recruits } \\
\text { moved to the first week from } \\
\text { week } 4\end{array}$ & $\checkmark$ & $\checkmark$ & $\checkmark$ \\
\hline $\begin{array}{l}\text { Accessible hand sanitizer at } \\
\text { all entrances and throughout } \\
\text { the main residence }\end{array}$ & $\checkmark$ & $\checkmark$ & $\checkmark$ \\
\hline $\begin{array}{l}\text { Prophylaxis of close contacts } \\
\text { (platoon members) of invasive } \\
\text { cases }\end{array}$ & $\checkmark$ & $\checkmark$ & $\checkmark$ \\
\hline $\begin{array}{l}\text { Isolation during the first } 24 \\
\text { hours of antibiotic treatment }\end{array}$ & $\checkmark$ & $\checkmark$ & $\checkmark$ \\
\hline $\begin{array}{l}\text { Directly observed hand } \\
\text { washing prior to meals }\end{array}$ & $\checkmark$ & $\checkmark$ & $\checkmark$ \\
\hline $\begin{array}{l}\text { Asymptomatic GAS carriage } \\
\text { screening of staff }\end{array}$ & $\checkmark$ & $\checkmark$ & - \\
\hline $\begin{array}{l}\text { Emphasis placed on reporting } \\
\text { to the medical clinic early } \\
\text { when symptomatic }\end{array}$ & $\checkmark$ & $\checkmark$ & $\checkmark$ \\
\hline $\begin{array}{l}\text { Social distancing where } \\
\text { possible, maintaining a } \\
\text { two-metre distance when } \\
\text { speaking in a raised voice }\end{array}$ & $\checkmark$ & $\checkmark$ & $\checkmark$ \\
\hline $\begin{array}{l}\text { Permission to "break rank" } \\
\text { when standing at attention to } \\
\text { "cover a cough" }\end{array}$ & $\checkmark$ & $\checkmark$ & $\checkmark$ \\
\hline $\begin{array}{l}\text { No sharing of personal } \\
\text { products (e.g. canteens) }\end{array}$ & $\checkmark$ & $\checkmark$ & $\checkmark$ \\
\hline $\begin{array}{l}\text { Increase influenza } \\
\text { immunizations to prevent } \\
\text { future outbreaks }\end{array}$ & - & - & $\checkmark$ \\
\hline $\begin{array}{l}\text { Reinforcement of need for } \\
\text { antibiotic compliance among } \\
\text { recruits }\end{array}$ & $\checkmark$ & $\checkmark$ & $\checkmark$ \\
\hline $\begin{array}{l}\text { Town halls to emphasize } \\
\text { control measures needed }\end{array}$ & - & $\checkmark$ & - \\
\hline $\begin{array}{l}\text { Triaging using a modified } \\
\text { Mclsaac scoring system with a } \\
\text { lower threshold to swab and } \\
\text { to treat on spec during an } \\
\text { outbreak }\end{array}$ & - & $\checkmark$ & $\checkmark$ \\
\hline $\begin{array}{l}\text { Enhanced daily cleaning by } \\
\text { recruits from once a day to } \\
\text { two to three times a day }\end{array}$ & - & $\checkmark$ & $\checkmark$ \\
\hline $\begin{array}{l}\text { MAP to recruits and } \\
\text { instructors (penicillin G } \\
\text { benzathine and azithromycin) }\end{array}$ & - & $\checkmark$ & - \\
\hline $\begin{array}{l}\text { MAP to recruits only } \\
\text { (penicillin G benzathine and } \\
\text { azithromycin) }\end{array}$ & - & - & $\checkmark$ \\
\hline
\end{tabular}


With a second GAS outbreak occurring in just over a year following the initial outbreak, and with a rising number of pharyngitis cases despite standard control measures, a voluntary MAP program was launched for the first time in CAF in an effort to stop continued GAS transmission. All recruits and instructors received a group briefing from a physician detailing the increased risk of contracting GAS at CFLRS, the modes of transmission and the applicable preventive measures, including MAP. A physician then met with each recruit/instructor individually in a private area to answer questions, review the consent form prior to signing and elicit information about any possible allergies. Refusals remained private between the physician and the recruit/instructor, without reprisal from their chain of command. Current recruits and instructors were offered 1.2 million units of PGB intramuscular. In the case of PGB refusal or penicillin allergic individuals, $500 \mathrm{mg}$ of azithromycin orally once weekly for four consecutive weeks was offered. In addition, given the dynamic rotation of the recruit population, all incoming recruits were offered MAP within two to three days of arrival.

From March 7 to May 28, 2018, 2,507 recruits and 200 instructors received MAP (Table 2). A precipitous drop in GAS pharyngitis was noted with no new iGAS/severe GAS (sGAS) cases occurring after March 10, 2018 (Figure 1). Six serious adverse events related to MAP administration included the following: one compartment syndrome with rhabdomyolysis and subsequent

Table 2: Mass antibiotic prophylaxis administration and adverse events by outbreak at the Canadian Forces Leadership and Recruit School, 2018-2019

\begin{tabular}{|c|c|c|c|c|c|}
\hline \multirow{2}{*}{$\begin{array}{c}\text { MAP } \\
\text { administration } \\
\text { details }\end{array}$} & \multicolumn{5}{|c|}{ Adverse events } \\
\hline & $\begin{array}{c}\text { Outbreak } \\
1\end{array}$ & $\begin{array}{c}\text { Outbreak } \\
2\end{array}$ & $\begin{array}{l}\text { Increase in } \\
\text { pharyngitis }\end{array}$ & $\begin{array}{c}\text { Outbreak } \\
3\end{array}$ & $\begin{array}{l}\text { MAP } \\
2019\end{array}$ \\
\hline $\begin{array}{l}\text { Outbreak } \\
\text { duration }\end{array}$ & $\begin{array}{l}\text { December } \\
2016 \text { to May } \\
2017\end{array}$ & $\begin{array}{l}\text { February } \\
11 \text { to } \\
\text { March 11, } \\
2018\end{array}$ & $\begin{array}{l}\text { July } 29 \text { to } \\
\text { August } 26 \text {, } \\
2018\end{array}$ & $\begin{array}{l}\text { November } \\
18 \text { to } \\
\text { December } \\
9,2018\end{array}$ & N/A \\
\hline $\begin{array}{l}\text { MAP } \\
\text { administration } \\
\text { period }\end{array}$ & $\begin{array}{l}\text { MAP not } \\
\text { used }\end{array}$ & $\begin{array}{l}\text { March } 7 \\
\text { to May 28, } \\
2018\end{array}$ & $\begin{array}{l}\text { August } 27 \text { to } \\
\text { October } 9, \\
2018\end{array}$ & $\begin{array}{l}\text { December } \\
5 \text { to } 7 \\
2018\end{array}$ & $\begin{array}{l}\text { January } \\
8 \text { to } \\
\text { November } \\
18,2019^{a}\end{array}$ \\
\hline MAP ta & $\begin{array}{l}\text { MAP not } \\
\text { used }\end{array}$ & $\begin{array}{l}\text { Recruits } \\
\text { and } \\
\text { instructors }\end{array}$ & Recruits only & $\begin{array}{l}\text { Recruits } \\
\text { only }\end{array}$ & $\begin{array}{l}\text { Recruits } \\
\text { only }\end{array}$ \\
\hline \multicolumn{6}{|c|}{ Penicillin $\mathrm{G}$ benzathine doses administered } \\
\hline Recruits (n) & N/A & 2,226 & 1,411 & 13 & 5,629 \\
\hline Instructors (n) & N/A & 172 & $\mathrm{~N} / \mathrm{A}$ & N/A & N/A \\
\hline \multicolumn{6}{|c|}{ Azithromycin prescribed } \\
\hline Recruits (n) & N/A & 281 & 252 & 645 & 836 \\
\hline Instructors (n) & N/A & 28 & $\mathrm{~N} / \mathrm{A}$ & N/A & N/A \\
\hline \multicolumn{6}{|l|}{ Refusal number } \\
\hline Recruits (n) & N/A & 27 & 81 & 46 & 141 \\
\hline Instructors (n) & N/A & 15 & $\mathrm{~N} / \mathrm{A}$ & N/A & $\mathrm{N} / \mathrm{A}$ \\
\hline \multicolumn{6}{|l|}{ Coverage } \\
\hline Recruits (\%) & N/A & 99.0 & 95.4 & 93.5 & 96.9 \\
\hline Instructors (\%) & N/A & 93.0 & $\mathrm{~N} / \mathrm{A}$ & $\mathrm{N} / \mathrm{A}$ & $\mathrm{N} / \mathrm{A}$ \\
\hline
\end{tabular}

Abbreviations: MAP, mass antibiotic prophylaxis; N/A, not applicable

a MAP is ongoing acute kidney injury; one hematoma at the injection site; one excess vomiting; one cellulitis; and two anaphylactic reactions. Other side effects included vasovagal episodes and pain at the injection site requiring medical attention.

\section{Pharyngitis increase of concern}

In August 2018, an increase in pharyngitis cases recurred at CFLRS. Despite re-emphasizing previously implemented control measures (Table 1), the ARD and ASD indices continued to rise and the number of GAS-positive swabs increased to $56.7 \%$ $(n=17 / 30)$ from August 12 to 18,2018 . Voluntary MAP was once again offered to all 1,663 current and incoming recruits from August 27 to October 9, 2018. Of the 1,411 recruits that received PGB, 31 (2.2\%) recruits experienced lightheadedness, five $(0.35 \%)$ recruits had a vasovagal response, two $(0.14 \%)$ recruits had nausea and two $(0.14 \%)$ recruits reported paresthesia/pain in the lower extremity. The genotyping of GAS isolates from recruits during this period of increased pharyngitis indicated emm6.4 (52 of 54 isolates).

\section{Outbreak 3}

Just short of two months from the last MAP session, the ARD indices increased above set thresholds for two consecutive weeks at the end of November 2018. During a two-week period, $79.7 \%(n=47 / 59)$ of throat swabs were GAS-positive. On December 2, 2018, a recruit was hospitalized for pneumonia and a GAS-positive pulmonary empyema; in addition, three severe non-invasive GAS infections were reported. Genotyping of all recruit throat cultures for the week of December 2 to 8 , 2018 ( $n=13$ ) were emm6.4, including the iGAS and sGAS cases. Given the impending closure of the school for holidays from December 12 to January 7, 2019, and the logistics involved in being able to administer PGB, $500 \mathrm{mg}$ azithromycin orally once weekly for two weeks was prescribed to 645 recruits (Table 2).

With three GAS outbreaks within a two-year period among recruits at CFLRS, in addition to the increase in GAS pharyngitis infections in August 2018, a decision was made in consultation with local and provincial public health authorities to administer MAP to recruits on a continuous basis. Adverse/side effects have remained low (Table 3 ) and there have been no prophylaxis failures. All breakthrough GAS pharyngitis cases had either not received MAP (i.e. refused) or had received MAP well beyond the period of effectiveness (more than four weeks). For 2019, there were only 11 GAS-positive throat cultures among recruits for the first half of the year and there have been no GAS-positive throat swabs since the third week of July 2019.

\section{Phylogenetic analysis of Group A Streptococcus-positive isolates}

A phylogenetic tree of GAS emm6.4 isolates (Figure 2) collected from across Canada from January 2012 to January $2020(n=403)$ consists of three major lineages of strains and an overall average 
Table 3: Mass antibiotic prophylaxis adverse/side effects in recruits who sought medical attention at the health services clinic, Canadian Forces Leadership and Recruit School, January 8-November 18, 2019

\begin{tabular}{|c|c|c|}
\hline \multirow{2}{*}{$\begin{array}{c}\text { Mass antibiotic } \\
\text { prophylaxis } \\
\text { adverse/side } \\
\text { effects }\end{array}$} & \multicolumn{2}{|c|}{$\begin{array}{l}\text { Total penicillin G benzathine doses } \\
\qquad N=5,629\end{array}$} \\
\hline & $n$ & $\%$ \\
\hline Vasovagal response & 69 & 1.2 \\
\hline Lightheadedness & 4 & $<0.01$ \\
\hline Rash & 4 & $<0.01$ \\
\hline $\begin{array}{l}\text { Anaphylaxis-like } \\
\text { reaction }\end{array}$ & 2 & $<0.01$ \\
\hline Numbness in leg & 2 & $<0.01$ \\
\hline Pain at injection site & 2 & $<0.01$ \\
\hline Anxiety & 1 & $<0.01$ \\
\hline
\end{tabular}

genetic difference of 18 single nucleotide variations (SNVs) and maximum distance of $71 \mathrm{SNV}$. The largest lineage consists predominantly of isolates from these outbreaks in Québec with older sporadic isolates generally located in the lower subclades, while the three more recent outbreak-related clades appear distantly in the upper portion of the tree. Within the major Québec lineage the isolates of the three military outbreak-related clades are closely related to the sporadic background strains; differing by an average of six SNVs (range 1-16 SNVs). Isolates associated with the original outbreak during May to June 2017 differed from isolates of outbreak 2 of February to March 2018 by one SNV; which in turn differed from isolates from the August 2018 pharyngitis increase plus outbreak 3 by $1-2$ SNVs. All emm6.4 isolates were multi-locus sequence type (MLST) ST-382 and possessed a S79A amino acid substitution in parC associated with fluoroquinolone resistance, and three isolates from August 2018 also contained mefAE associated with macrolide resistance. The superantigen toxin profile of the background sporadic and outbreak 1 strains included SpeA-C-G-H-I-K-SmeZ, whereas the strains of the later outbreaks 2 and 3 lacked the SpeH and Spel toxins.

\section{Discussion}

Between December 2016 and December 2018, CFLRS experienced three consecutive GAS outbreaks and one period of increased pharyngitis infections among recruits; all associated with type emm6.4. The outbreaks at CFLRS were unprecedented given no previous documented outbreaks in CAF recruit population. The commonly used non-pharmaceutical interventions were ineffective in preventing GAS transmission among recruits. It was only through implementation of MAP (PGB/azithromycin) with a corresponding high compliance rate that the outbreaks were quickly brought under control.
Figure 2: Maximum likelihood core single nucleotide variant phylogenetic tree of $S$. pyogenes emm6.4 isolates ${ }^{a}$ collected in Canada, January 2012-January $2020(n=403)$

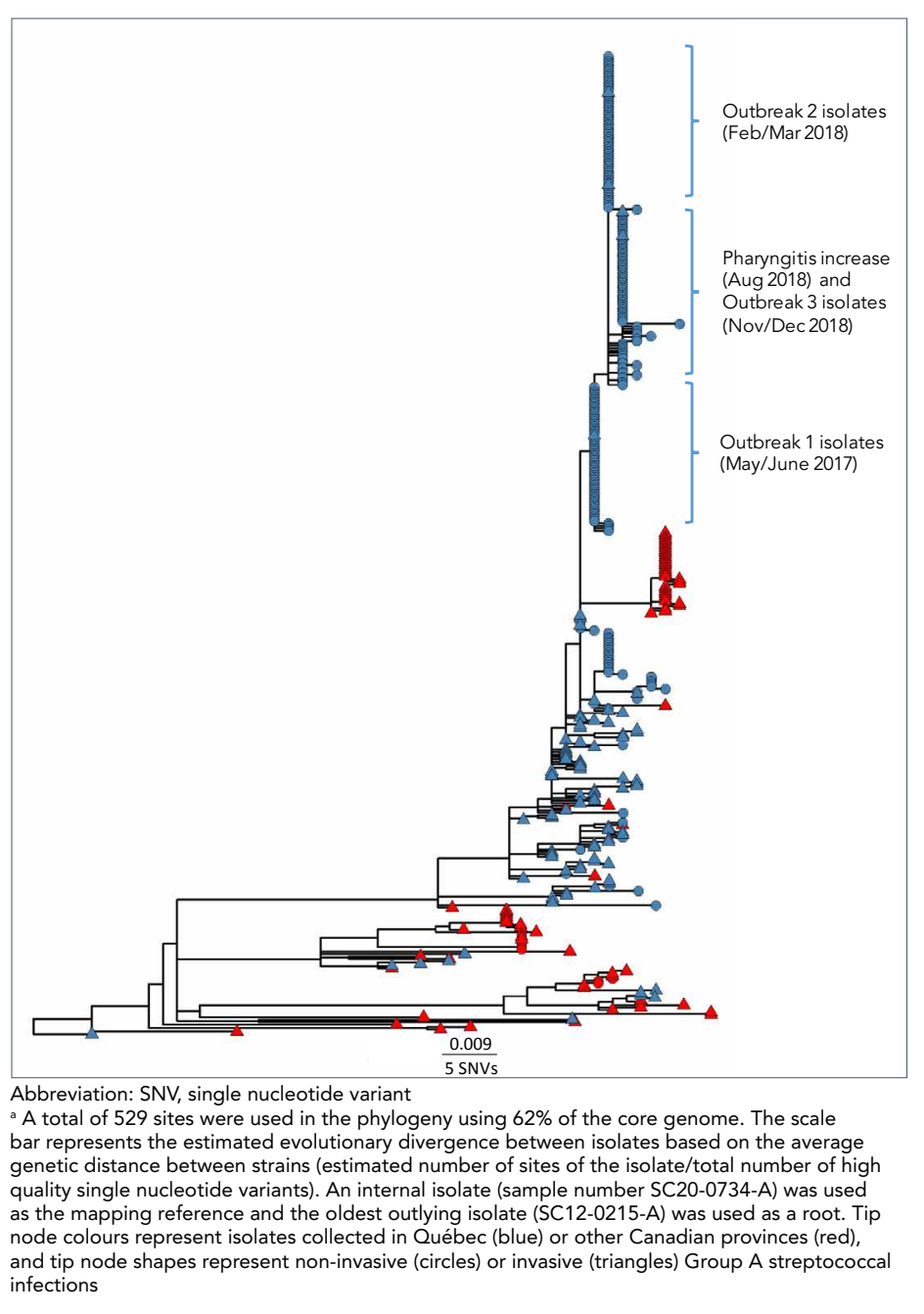

Elevated rates of streptococcal infections and GAS outbreaks at US military recruit training centres have been documented since the 1940 s and continue into the $21^{\text {st }}$ century $(15,16)$. The reason for the first GAS outbreak in CAF in 2016, and the successive outbreaks, is unknown. No factors that would increase the risk of transmission, such as a substantial increase in the recruit population, change in accommodations or training, or standard hygiene measures were observed. As well, the recruit population consists largely of young, healthy individuals. The introduction of a virulent strain as the cause of the outbreaks is possible since emm6.4 is a relatively rare GAS type in Canada compared with other emm types and immunity is likely low. Isolation of streptococcal emm6 accounted for only $1.9 \%$ of all invasive streptococcal emm types in Canada in 2017 (2). The introduction of a virulent strain, combined with risk factors favouring respiratory infection transmission (close contact during training, shared living accommodations, limited hours of sleep), 
in addition to the physical and psychological impact of basic training and hygiene practices, might have set up the perfect milieu for continued transmission.

Another hypothesis for the introduction of GAS emm6.4 was the possibility of an asymptomatic carrier. Since there is a constant rotation of new recruits coming into CFLRS and the predominant emm type persisted throughout the outbreaks, instructors who had close contact with recruits could be considered as a potential source. The strain of emm6.4 associated with the military outbreaks, while closely related to other GAS circulating in the local civilian population, was phylogenetically distinct from the sporadic background strains. Isolates of each successive outbreak differed by one SNV for an overall change of about two SNVs over the duration of the three outbreaks from May 2017 to August 2018, consistent with previously reported genetic drift estimates of about 1.7 SNVs per genome per year (17).

Pharyngeal GAS carriage among staff has been known to propagate outbreaks in hospitals and long term care facilities $(16,18,19)$. Instructors were targeted twice, on a voluntary basis, to assess GAS carriage status; however, only $40 \%$ of instructors who had contact with one or more invasive cases presented for screening in the first assessment and only two-thirds of all instructors participated after the second outbreak. Although three instructors were positive for emm6.4 during the second assessment, only one instructor successfully underwent eradication treatment. Without a near census of the carriage status of instructors, the contribution of asymptomatic GAS carriage to the continued transmission of GAS among recruits cannot be ruled out.

Numerous prevention and control measures were implemented and enhanced during each successive outbreak (Table 1).

Despite these measures, outbreaks of GAS and increased rates of pharyngitis continued at CFLRS. The reluctance of recruits to seek care early due to the ramifications on course completion was identified during the first outbreak and likely played a role in perpetuating the outbreaks.

In the US military, chemoprophylaxis was trialed during the 1950s and PGB was effective in reducing the incidence of streptococcal disease with only $0.86 \%$ of naval recruits having an adverse reaction (20). The PGB has been administered using various schedules (year round, seasonally and single versus tandem dose) depending on the recruit training centre in the US (7). Similarly, it was only through the administration of MAP that there was any precipitous and sustained fall in the ASD rate at CFLRS. The third GAS outbreak prompted the implementation of MAP year round. Although MAP is not without risk of significant adverse events, including anaphylaxis, the benefits were deemed to outweigh the risks. In addition, the development of antibiotic resistance with the use of a macrolide for penicillin allergic recruits was not regarded as a contraindication to its use since the total number of recruits going through basic training and receiving a macrolide for MAP was considered small compared to its use in the general Canadian population. Similar to our US counterparts, MAP has been well tolerated with very few side effects and has had little impact on successfully completing recruit training (Lu D, Strauss B, Simkus K, Tepper M, Gagnon F, Johnson N; unpublished results). Webber et al. noted in reviewing MAP use in US military training facilities that no case of anaphylaxis had been reported since active surveillance started in 1998 (7).

The ability to administer PGB to a large cohort of recruits had its challenges. Securing the required PGB doses and securing additional qualified healthcare workers to administer PGB took time to coordinate. As well, logistical issues such as space for the recruit briefing, space for the consent process and space for the administration of PGB to maintain privacy, as well as appropriate resuscitation equipment on site, was required. The start-up of each round of MAP was logistically difficult since all recruits (current and incoming) required MAP, compared with routine/ongoing MAP administration for which the necessary preparation was already in place and only incoming recruits required prophylaxis.

\section{Acute Respiratory Infection Surveillance Program}

The Acute Respiratory Infection Surveillance Program was implemented after the first outbreak to monitor for future respiratory outbreaks using thresholds defined by the US military. The ARD and ASD thresholds were effective at indicating increased GAS circulation and an impending outbreak; however, we were unable to prevent iGAS and sGAS cases among recruits in two of the outbreaks. Current thresholds should be reevaluated since only recruits who meet the Mclsaac score of $2-5$ are swabbed for GAS compared to $80 \%$ of US recruits (15).

\section{Strengths and limitations}

This paper describes the first time administration of MAP in a large cohort of healthy adults that resulted in high compliance, few side effects, and a reduction of GAS pharyngitis.

Recruits represent a unique population and results from the administration of MAP in terms of acceptance and compliance and the logistical capability to administer antibiotics to a large number of individuals may not be generalizable to other populations. Only MAP adverse/side effects that required medical attention were captured; therefore, underreporting of mild side effects is likely. In addition, the contribution of co-infections with other circulating viruses was not evaluated. Furthermore, the low voluntary participation of instructors to determine the GAS carriage rate meant that the contribution of a carrier to these outbreaks could not be ruled out. Lastly, adherence to control measures was not evaluated. 


\section{Conclusion}

Outbreaks of GAS can have severe consequences_including death. For the first time, CFLRS experienced three outbreaks and one period of elevated numbers of GAS pharyngitis infections in recruits over a two-year period-all linked to type emm6.4. Despite enhanced hygiene measures, only MAP was effective in interrupting the transmission of GAS in the recruit population.

\section{Authors' statement}

$B S, M T, D L, F G, E G$ and $K B$ were involved in the methodology, outbreak investigation and public health management MM managed the laboratory collection and reporting at the local level WD and IM managed the genomic sequencing of the isolates, produced the phylogenetic tree, and related interpretation considering the clinical data

BS summarized the data and wrote the first draft

All authors contributed to the review and revisions of the manuscript

\section{Competing interests}

None.

\section{Acknowledgements}

We would like to thank Dr. M St. Amour for her collaboration in the management of these successive outbreaks. We would also like to thank the healthcare personnel at 41 Health Services for their assistance in data collection, reporting, and outbreak management; especially, LCdr JL Plante, Capt N Johnson and Maj G Hautcoeur-Tedeschi. We are also appreciative of MWO T Pugh for her assistance in collating the mass antibiotic prophylaxis data and MC Lamontagne for her assistance with the Acute Respiratory Infection Surveillance Program.

\section{Funding}

This work was supported by the Department of National Defence.

\section{References}

1. Heymann DL. Streptococcal diseases. In Control of Communicable Diseases Manual, 20th ed., pp 581-589. Washington (DC): America Public Health Association, 2015.

2. Public Health Agency of Canada. National Laboratory Surveillance of Invasive Streptococcal Disease in Canada - Annual Summary 2017. Ottawa (ON): PHAC; 2019 (accessed 2020-02-15). https://www.canada.ca/en/ public-health/services/publications/drugs-health-products/ national-laboratory-surveillance-invasive-streptococca l-disease-annual-summary-2017.html
3. Pilon PA, Savard N, Aho J, Caron J, Urbanek A, Paré R, Le Guerrier P, Savard C, Hammond-Collins K, Tran CD, Allard R, Domingo MC. Invasive group A streptococcal infection outbreaks of typeemm118 in a long-term care facility, and of type emm74 in the homeless population, Montréal, Quebec. Can Commun Dis Rep 2019;45(1):26-31. DOI PubMed

4. Dickson C, Pham MT, Nguyen V, Brubacher C, Silverman MS, Khaled K, Hovhannisyan G. Community outbreak of invasive group A streptococcus infection in Ontario, Canada. Can Commun Dis Rep 2018;44(7/8):182-8. DOI PubMed

5. Teatero S, McGeer A, Tyrrell GJ, Hoang L, Smadi H, Domingo MC, Levett PN, Finkelstein M, Dewar K, Plevneshi A, Athey TB, Gubbay JB, Mulvey MR, Martin I, Demczuk W, Fittipaldi N. Canada-wide epidemic of emm74 Group A Streptococcus invasive disease. Open Forum Infect Dis 2018;5(5):ofy085. DOI PubMed

6. Dingle JH, Theordore J, Badger G, Beard JW, Cresy NL, Feller AE, Gordon I, Langmuir AD, Rammelkamp CH, Strauss $\mathrm{E}$, Talleck H. (Commission on Acute Respiratory Diseases). Acute respiratory disease among new recruits. Am J Public Health Nations Health 1946;36(5):439-50. DOI PubMed

7. Webber BJ, Kieffer JW, White BK, Hawksworth AW, Graf PC, Yun HC. Chemoprophylaxis against group A streptococcus during military training. Prev Med 2019;118:142-9. DOI PubMed

8. Thomas RJ, Conwill DE, Morton DE, Brooks TJ, Holmes CK, Mahaffey WB. Penicillin prophylaxis for streptococcal infections in United States Navy and Marine Corps recruit camps, 1951-1985. Rev Infect Dis 1988;10(1):125-30. DOI PubMed

9. Sanchez JL, Cooper MJ, Myers CA, Cummings JF, Vest KG, Russell KL, Sanchez JL, Hiser MJ, Gaydos CA. Respiratory infections in the U.S. military: recent experience and control. Clin Microbiol Rev 2015;28(3):743-800. DOI PubMed

10. Gray GC, McPhate DC, Leinonen M, Cassell GH, Deperalta EP, Putnam SD, Karcher JA, Sawyer MH, Laurila A, Connor JD. Weekly oral azithromycin as prophylaxis for agents causing acute respiratory disease. Clin Infect Dis 1998;26(1):103-10. DOI PubMed

11. Public Health Agency of Canada. Supplement: Guidelines for the prevention and control of invasive group A streptococcal disease. https://www.canada.ca/en/public-health/services/ reports-publications/canada-communicable-disease-reportccdr/monthly-issue/2006-32/canada-communicabl e-disease-report.html

12. Fine $A M$, Nizet $V$, Mandl KD. Large-scale validation of the Centor and Mclsaac scores to predict group A streptococcal pharyngitis. Arch Intern Med 2012 Jun;172(11):847-52. DOI PubMed

13. Centers for Disease Control and Prevention. Streptococcus Laboratory: Protocol for emm typing. Atlanta (GA): CDC; 2018 (accessed 2020-03-06). https://www.cdc.gov/streplab/ groupa-strep/emm-typing-protocol.html 
14. Hammond-Collins K, Strauss B, Barnes K, Demczuk W, Domingo MC, Lamontagne MC, Lu D, Martin I, Tepper M. Group A streptococcus outbreak in a Canadian Armed Forces training facility. Mil Med 2019;184(3-4):e197-204. DOI PubMed

15. Lee SE, Eick A, Ciminera P. Respiratory disease in Army recruits: surveillance program overview, 1995-2006. Am J Prev Med 2008;34(5):389-95. DOI PubMed

16. Smith A, Li A, Tolomeo O, Tyrrell GJ, Jamieson F, Fisman D. Mass antibiotic treatment for group A streptococcus outbreaks in two long-term care facilities. Emerg Infect Dis 2003;9(10):1260-5. DOI PubMed

17. Dickinson $H$, Reacher $M$, Nazareth $B$, Eagle $H$, Fowler $D$, Underwood A, Chand M, Chalker V, Coelho J, Daniel R, Kapatai G, Al-Shabib A, Puleston R. Whole-genome sequencing in the investigation of recurrent invasive group $A$ streptococcus outbreaks in a maternity unit. J. Hosp. Infect. 2019;101(3):320-6. DOI

\section{Appendix A: Background-Canadian Forces Leadership and Recruit School}

The Canadian Forces Leadership and Recruit School (CFLRS), located in St-Jean-Sur-Richelieu, Québec (Canada) is the only facility offering basic military training for all members of the Canadian Armed Forces Regular Force component. More than 5,000 recruits cycle through CFLRS each year. Recruits are housed in a self-contained dormitory style residence within either an individual open cubicle-like space with dividers or in a small single room with shared common spaces for their 10 or

12 week basic training session. The school also has classrooms, a gymnasium and a cafeteria; all housed within the same complex. Recruits are grouped into platoons of approximately 60, and spend the majority of their days in close proximity to one another within their platoon. There is also mixing between platoons in common areas and during certain training sessions. Recruits remain on base at all times for the first five weeks. All primary care is provided by the base medical clinic, which is located in close proximity to the school. When the base medical clinic is closed, civilian health care facilities are used.
18. Mahida N, Prescott K, Yates C, Spencer F, Weston V, Boswell T. Outbreak of invasive group A streptococcus: investigations using agar settle plates detect perineal shedding from a healthcare worker. J Hosp Infect 2018;100(4):e209-15. DOI PubMed

19. Inkster $T$, Wright $P$, Kane H, Paterson E, Dodd S, Slorach J. Successive outbreaks of Group A Streptococcus (GAS) in care of the elderly settings; lessons learned. J Infect Prev 2012;13(2):38-43. DOI

20. Brooks TJ Jr, Moe TI. Use of benzathine penicillin G in carriers of group a beta-hemolytic streptococci. J Am Med Assoc 1956;160(3):162-5. DOI PubMed

\section{Appendix B: Case definition for confirmed and probable severe non-invasive Group A Streptococcus}

- Confirmed, severe non-invasive Group A Streptococcus (GAS) case:

An individual at the Canadian Forces Leadership and Recruit School (CFLRS) with a laboratory confirmed GAS infection isolated from a non-sterile site requiring an overnight hospitalization since December 2016.

- Probable, severe non-invasive GAS case:

An individual at CFLRS who had symptoms compatible with a non-invasive GAS infection requiring overnight hospitalization, but lacking laboratory confirmation of GAS infection, since December 2016. 